\title{
The Differences in Positive Parenting According to Male and Female Student in Bandung
}

\author{
$1^{\text {st }}$ Hendriati Agustiani \\ Faculty of Psychology \\ Universitas Padjadjaran \\ Jatinangor-Sumedang, Indonesia \\ hendriati.agustiani@unpad.ac.id
}

\author{
$2^{\text {nd }}$ Ratna Jatnika \\ Faculty of Psychology \\ Universitas Padjadjaran \\ Jatinangor-Sumedang, Indonesia
}

\author{
$3^{\text {rd }}$ Yanti Rubiyanti \\ Faculty of Psychology \\ Universitas Padjadjaran \\ Jatinangor-Sumedang, Indonesia
}

\begin{abstract}
This research is a comparative study to determine differences in perceptions of male and female students regarding Father's Positive Parenting and Mother's Positive Parenting. Positive parenting was measured using a questionnaire consisting of 75 items. Data collection was carried out on 93 students in junior high schools in Bandung, consisting of 33 male students and 60 female students. The data obtained were calculated using an independent sample ttest. The results of data processing showed that there were significant differences in male and female students in perceiving father's positive parenting (Mean Male $=\mathbf{2 . 1 2 9 0}$; Mean Female $=2.3405 ; t=-2.561 ; p=0.012$ ). Likewise, the results of data processing showed that there were significant differences in male and female students in perceiving mother's positive parenting (Mean male $=2.3969$; Mean female $=2.6107 ; t=-3.138 ; p=0.002$ ). It seems that nowadays, parents are needed to be directly involved and more aware of their adolescent's needs and expectations in many things whether formally (educational matters) or informally (interpersonal matters), which means that parents need to always develop themselves by actively seeking information about the things that come to be "the world" for their adolescents. Boundaries or rules set for girls and boys very much needed to be given in different ways. Girls can interpret parental boundaries as a form of attention and affection, while boys tend to interpret them as a form of restrictions, and for sure boundaries set for boys need to be given through explanations and discussion until they understand the meaning of the boundaries itself.
\end{abstract}

Keywords-Positive Parenting, Male, Female, Student, Bandung

\section{INTRODUCTION}

In an essay titled "The Problem of Generations," a sociologist, Mannheim (1952), introduced his theory about generations. He said that people in this world will influence each other and develop the same character because they experience the same socio-historical era. It means, people of World War II and people after WW II would certainly have different characters, even though they influenced one another. Based on that theory, sociologists differentiate people into several generations: Great Depression Era Generation, World War II Generation, Post WWII
Generation, Baby Boomer I Generation, Baby Boomer II Generation, Generation X, Generation Y is also known as the Millennial, and Generation Z. These classifications are usually based on the birth year range of people.

Generation Z or also called as the Net Generation is the generation that already connected to the internet, gadget and technology ever since they were born, which before that kind of technology had not been developed so rapidly in the human life (Don Tapscott, 2009). This generation has broader insight and literation than those of their parents in the use of digital media. They were born in the age of the internet, computers, and cellphones. In other words, this generation was born in the digital era. Adolescents in Generation $\mathrm{Z}$ right now are between 11 to 22 years old.

According to Steinberg (2014), adolescent age is in a range between 13 to 19 years old. Adolescent according to Steinberg, is a period in which biological, psychological, social and economic changes occur. Adolescent age is a transition from childhood to adulthood. Santrock (2007) identified adolescent period as a development transition between childhood and adulthood that involves biological, cognitive, and socio-emotional change, with age range started from 10 to 13 years old and ended around the age of 18 to 22 years, and marked by getting interested in career and job, in having a serious relationship with the opposite sex, and in exploring other self-potentials.

In relation to adolescent personality, there are two factors that influence its development, which is an individual factor (internal) and social environment factor (external). In the individual factor, cognition and affection play a big role. Through cognitive abilities, an individual can observe, evaluate and judge own abilities. While in a social environment factor, influence comes from family, school, and society. The family environment is relating to parents attitude of acceptance and parenting style in dealing with adolescent behaviour. Parents and school environment determine the shaping of adolescent personality. School is the first environment for the adolescent to receive academic and social experiences. Society environment is relating to cultural and religious values developed in the society, 
including economic situation and technology transformation.

Regarding current development, generation $\mathrm{Z}$ brings changes to the ways of parenting. There is a phenomenon where parents and educators undergo a transition of approach in educating and parenting generation $\mathrm{Z}$ adolescents. One research study relating to adolescent development is positive parenting. Positive parenting describes a positive relationship between parents (father and mother) and adolescents that contains parent's involvement and acceptance of their adolescents, parent's strict attitude and supervision, parent's restrictions on the adolescents' environment, parent's giving freedom to encourage adolescent's autonomy. (Chao, 2001; Gray \& Steinberg, 1989; Steinberg, Lamborn, Dornbusch, \& Darling, 1992 in Seginer, 2009). Positive parenting can be acquired based on the information of how adolescents perceive their parent's parenting style.

In positive parenting, a presence of acceptance, support, supervision and freedom given by parents has an impact on the parents-adolescent relationship, including in this matter on how parents support their teenagers to build a positive attitude toward their personality development. Freedom to experience online media can make adolescents getting closer to their parents, but on the other hand, it makes them detached from parental influence because many parents become unaware of what online media experiences that their adolescents have gone over (Don Tapscott). Therefore, through positive parenting approach, parents can give support, supervision, boundaries and freedom to adolescents.

Generation $\mathrm{Z}$ adolescents became a significant challenge in the world of education and parenting. It is because there are more dangerous risks in online media than the positive benefit of it. In daily lives, adolescent boys and girls can be potential victims of online games, pornography, and other dangerous risks as the consequence of online media. Parents, in this case, should be aware of how important their role is in the development of the identity of their adolescents and to keep a positive judgment on support and supervision in the family.

According to Santrock (2012), children have typical characteristics in accordance with their gender. In childhood, their masculine and feminine behaviour corresponds to their gender. Boys are said to have a good adaptation when they show independent, aggressive and strong behaviour. While girls are considered well adapted when they show dependency, compassionate and no interest in strength. A study showed few differences were found in parental control with boys and girls. Parents were slightly more controlling with boys than with girls. Other study showed that parenting could influence a child's gender development (Leaper, 2014).
The differences in parenting for boys and girls need to be very well studied so parents can prepare the most suitable parenting for generation $\mathrm{Z}$ adolescents. One way to know how the best gender-based parenting for generation $\mathrm{Z}$ adolescents is, first by knowing how adolescent boys and girls perceived their parent's parenting which in this case, the positive parenting. Based on that information, a better and more suitable way of parenting can be developed for these adolescents. Therefore, in this study, we want to know the differences in perception between adolescent boys and girls. As for the formulation of this study, "Is there a difference in perception of Father's Positive Parenting and Mother's Positive Parenting between adolescent boys and girls in Bandung district?

\section{METHOD}

This study is a cross-sectional comparative study to determine differences in perceptions of adolescent boys and girls about Father's Positive Parenting and Mother's Positive Parenting. Positive parenting is measured using a questionnaire consisting of 75 items. The Positive Parenting Questionnaire consists of the following aspects:

- Acceptance including parents being present during difficult times, giving support when a child feels like a failure, providing help, listening to child's complaints, showing a pleasant attitude toward a child and not setting a target outside child's competencies.

- Supervision including parents knowing a child's ambition and interest, being interested in child's problem with friends, attentive to school achievements, satisfying a child's curiosity and letting a child choose what to be interested in.

- Limit setting including parents setting a rule for a child's use of time to study and play, setting a rule for activities that child can follow, and setting boundaries for a child's relationship with friends.

- Autonomy granting including parents giving freedom for a child to make their own decisions, giving a chance for the child to speak, compromising to the child's different opinions and encouraging autonomy.

(Chao, 2001; Gray \& Steinberg, 1989; Steinberg, Lamborn, Dornbusch, \& Darling, 1992 in Seginer, 2009)

Data collection was performed on 93 teenage students at a Junior High School in Bandung district, consisting of 33 male students and 60 female students. The data obtained were calculated using an independent sample t-test using SPSS 25 for Windows.

\section{RESULT}

Data processing gives the following results:

TABLE I. POSITIVE PARENTING ACCORDING TO MALE AND FEMALE STUDENT

\begin{tabular}{|l|l|r|r|r|}
\hline Variable & Sex & $\mathrm{N}$ & Mean & Standard Deviation \\
\hline Father's Positive Parenting & Male & 33 & 2.1296 & .40787 \\
\cline { 2 - 5 } & Female & 60 & 2.3405 & .36414 \\
\hline Mother's Positive & Male & 33 & 2.3969 & .36248 \\
\cline { 2 - 5 } Parenting & Female & 60 & 2.6107 & .28500 \\
\hline
\end{tabular}


TABLE II. THE DIFFERENCES IN POSITIVE PARENTING ACCORDING TO MALE AND FEMALE STUDENT

\begin{tabular}{|l|l|r|r|r|r|}
\hline Variable & Sex & Mean & Standard Deviation & $\mathrm{t}$ & $\mathrm{P}$ \\
\hline Father's Positive Parenting & Male & 2.1296 & .40787 & -2.561 & $.012^{*}$ \\
\cline { 2 - 4 } & Female & 2.3405 & .36414 & & \\
\hline \multirow{2}{*}{ Mother's Positive parenting } & Male & 2.3969 & .36248 & -3.138 & $.002^{*}$ \\
\cline { 2 - 4 } & Female & 2.6107 & .28500 & & \\
\hline$*: \mathrm{p}<0.05$ & & & & & \\
\hline
\end{tabular}

Based on Table I and Table II, it is clear that female students have better perception than male students of a father's positive parenting and the mother's positive parenting.

\section{DISCUSSION}

Research result shows that female students have better perception than the male students of a father's positive parenting and also the mother's positive parenting. This means that female students considered their parents both mother and father to be more present during difficult times, give them support when they feel like a failure, provide them help, listen to their complaints, show a pleasant attitude and not setting a target outside their abilities. Female students also considered their parents acknowledge their ambitions and interests, being interested in their problems with their friends, attentive to their school achievements, satisfy their curiosity and let them choose what they are interested in. Research result also shows that female student as compared to male students considered their parents had set them a rule for their use of time to learn and play, set a rule for activities that they can follow, and set boundaries for their relationship with their friends. Female students as compared to male students, also considered their parents to give them the freedom to make their own decisions, give them a chance to speak out, would compromise to different opinions and encourage them to be more autonomous.

This research result can be used as one of the input to prepare the most suitable parenting for generation $\mathrm{Z}$ adolescents both boys and girls. Different parenting for adolescent boys and girls need to be developed. From the discussion above it seems obvious that nowadays parents are really needed to be directly involved and more aware of their adolescent's needs and expectations in many things whether formally (educational matters) or informally (interpersonal matters). Meaning that parents need to always develop themselves by actively seeking information about the things that come to be "the world" for their adolescents. Boundaries or rules set for girls and boys very much needed to be given in different ways. Girls can interpret parental boundaries as a form of attention and affection, while boys tend to interpret them as a form of restrictions, and for sure boundaries set for boys need to be given through explanations and discussion until they understand the meaning of the boundaries itself.

\section{CONCLUSION}

Female students have better perception than male students of a father's positive parenting and the mother's positive parenting. This difference is found in the acceptance, supervision, limit setting and autonomy granting aspects.

\section{REFERENCES}

[1] Endendijk J 2016 PLoS ONE. Jurnal Gender Differentiated Parenting Revisited: Meta-Analysis Reveals Very Few Differences in Parental Control of Boys and Girls 11715

[2] Leaper, Campbell 2014 Encyclopedia on early childhood development Parents Socialization of Gender in Children 4

[3] Mannheim, Karl, 1952. Essays on the Sociology of Knowledge: Collected Works, 5 276-32

[4] Moller, Eline 2013 Journal of Experimental Psychopathology 4 88-117

[5] Santrock J 2007 Adolescence (New York: Mc Graw Hill International)

[6] Santrock J 2012 Adolescence (New York: Mc Graw Hill international)

[7] Seginer R 2009 Future Orientation. Developmental and Ecological Perspectives (New York: Springer)

[8] Steinberg L 2014 Adolescence (New York: Mc Graw Hill international)

[9] Tapscott D 2009 Grown Up Digital. How the Net Generation is Changing Your World (New York: Mc Graw Hill) 